\title{
Susceptibility of the Median Palmar Cutaneous Nerve in Carpal Tunnel Syndrome
}

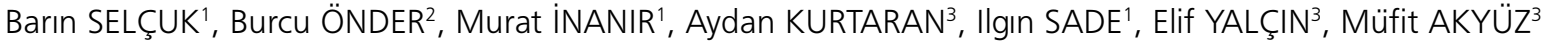 \\ 'Deparment of Physical Medicine and Rehabilitation, Kocaeli University Faculty of Medicine, Kocaeli, Turkey \\ ${ }^{2}$ Clinic of Physical Medicine and Rehabilitation, Çorlu State Hospital, Çorlu, Turkey \\ ${ }^{3}$ Clinic of Physical Medicine and Rehabilitation, Ankara Physical Medicine and Rehabilitation Training and Research Hospital, Ankara, Turkey
}

\begin{abstract}
Objective: The aim of this study was to investigate the susceptibility of the palmar cutaneous branch of median nerve (PCBm) in carpal tunnel syndrome (CTS).

Material and Methods: Electrophysiological assesment of the PCBm sensory conduction study in electrodiagnostically defined carpal tunnel syndrome extremities.

Results: We examined 83 hands with electrodiagnostically defined CTS and 33 control extremities. While none of the extremities without carpal tunnel syndrome shows pathological PCBm sensory conduction study, $62.7 \%$ (52) of the extremities with carpal tunnel syndrome showed pathologic conduction and there was statistically significant difference between the groups $(p<0.05)$. PCBm sensory nerve action potential (SNAP) was obtained in all of the extremities with mild carpal tunnel syndrome. The SNAP could not be obtained in 20\% (5/25) extremities with moderate carpal tunnel syndrome and in extremities with $46.1 \%(6 / 13)$ severe carpal tunnel syndrome. On evaluation according to the severity of carpal tunnel syndrome; $37.2 \%(16 / 43)$ of the cases with mild carpal tunnel syndrome showed electrophysiological pathology in PCBm sensory conduction study, and it was detected in $92.6 \%(27 / 25)$ of the cases with moderate carpal tunnel syndrome, and $84.6 \%(11 / 13)$ of the cases with severe carpal tunnel syndrome

Conclusion: PCBm is frequently effected in patientes with CTS and suggest that this nerve not ideal as a comparator nerve for the electrophysiological diagnosis of CTS.

Keywords: Median palmar cutaneous nerve, carpal tunnel syndrome, electrophysiology, ENMG
\end{abstract}

\section{Introduction}

Carpal tunnel syndrome (CTS) is the most common peripheral mononeuropathy with a development risk rate of $10 \%$ during the whole life (1). It is a frequently seen syndrome characterized by pain, numbness, and a tingling sensation in the hands due to the compression of the median nerve in the wrist (2). In CTS, typical sensory distribution is restricted to the volar aspect of the palm, the first 3 fingers, and the lateral region of the $4^{\text {th }}$ finger. The protection of the thenar area innervated by the palmar cutaneous branch of the median nerve $(\mathrm{PCBm})$ that branches before entering the carpal tunnel is important in clinical and electrophysiological evaluations (3).

The palmar cutaneous branch of the median nerve branches off before the median nerve enters the carpal tunnel, and it provides sensory innervations of the thenar region; therefore, it is not affected by CTS (4). Owing to this feature, studies comparing $\mathrm{PCBm}$ with the main median nerve are recommended

Address for Correspondence: Barın Selçuk, MD, Kocaeli Üniversitesi Tıp Fakültesi, Fiziksel Tıp ve Rehabilitasyon Anabilim Dalı, Kocaeli, Türkiye. Phone: +90 2623038633 E-mail: barinselcuk@yahoo.com

Received: January 2014 Accepted: April 2014

OCopyright 2015 by Turkish Society of Physical Medicine and Rehabilitation - Available online at www.ftrdergisi.com

Cite this article as: 
for the diagnosis of CTS and for revealing the presence of CTS against the background of polyneurotherapy $(5,6)$. However, reports of PCBm entrapments or susceptibility with CTS prevented this nerve from being included among routine examinations in comparative studies (7-9).

In this study, it is aimed to find whether PCBm sensory nerve action potentials are affected in CTS patients.

\section{Material and Methods}

In this study, 116 extremities of 58 patients who applied to the electrophysiology laboratory of Ankara Physical Medicine and Rehabilitation Training and Research Hospital with the prediagnosis of CTS between April 2011 and December 2011 and who had CTS, electrophysiologically detected, in at least one extremity in accordance with the criteria of the study were considered. Ethics committee approval from the hospital and written informed consent from patients were obtained for the study.

While patients with complaints of numbness and tingling in the hands and sensorial complaints at night and in the morning were included in the study, those with a history of suspected polyneuropathy, neck pain, and radiculopathy and whose neurological examination revealed pathological finding were excluded. Patients who had polyneuropathy and radiculopathy findings in their electrophysiological examination were also excluded from the study.

Electrophysiological evaluations were performed by the same researcher using Dantec Keypoint 4c (The Dantec Keypoint 4c EMG/NCS/EP, Skovlunde, Denmark) electromyography device. The hands of the patients were heated, and the temperature was kept stable between $30^{\circ} \mathrm{C}$ and $32^{\circ} \mathrm{C}$. Sural nerve sensory conduction and tibial and peroneal nerve motor conduction studies at least in one lower extremity and median and ulnar nerve motor and sensory conduction studies and palmar cutaneous nerve sensory conduction studies in both upper extremities were performed in all patients. In motor conduction studies, motor distal latency (MDL) and compound muscle action potential (CMAP) values were recorded for the median and ulnar nerves by stimulating at the level of the wrist and antecubital region in the abductor pollicis brevis (APB) and abductor digiti minimi (ADM) muscles in the upper extremity. In the lower extremity, tibial nerve MDL and CMAP values obtained from the abductor hallucis muscle by stimulating at the level of the wrist and popliteal region and peroneal nerve MDL and CMAP obtained from the extensor digitorum brevis (EDB) muscle by stimulating at the level of the wrist and the head of the fibula were recorded. A sural nerve sensory conduction study was recorded to be antidromic by stimulating $14-15 \mathrm{~cm}$ proximal to the back of the lateral malleolus. Antidromic sensory conduction velocities and response amplitudes for the median nerve in the $1^{\text {st }}$ finger and for the ulnar nerve in the $5^{\text {th }}$ finger were recorded. Antidromic sensory conduction velocities for the median and ulnar nerves in the $4^{\text {th }}$ finger were recorded, and the interpeak latency difference was calculated. The sensory conduction study of the palmar cutaneous nerve was conducted using the antidromic technique defined by Chang and Lien (5) in 1991. In this technique, recording was performed in the middle point of the thenar muscles via a superficial electrode, and a stimulus was applied from $10 \mathrm{~cm}$ proximal and from the middle of the fore arm.

In motor and sensory conduction studies, standard device parameters were used. For motor conduction studies, the parameters were as follows: the severity of stimulus: 1-100 mA, the duration of stimulus: $0.1 \mathrm{~ms}$, low frequency filter: $3 \mathrm{~Hz}$, high frequency filter: $10 \mathrm{kHz}$, sensitivity: $2 \mu \mathrm{V}$, and sweep rate: $20 \mathrm{~ms}$ ( $2 \mathrm{~ms} / \mathrm{div})$. The parameters for the sensory conduction study were as follows: the severity of stimulus: $1-100 \mathrm{~mA}$, the duration of stimulus: $0.1 \mathrm{~ms}$, low frequency filter: $20 \mathrm{~Hz}$, high frequency filter: $2 \mathrm{kHz}$, sensitivity: $20 \mu \mathrm{V}$, and sweep rate: $10 \mathrm{~ms}$ ( $1 \mathrm{~ms} / \mathrm{div}$ ).

Patients diagnosed with CTS were classified into the following three groups: mild (decreased sensory conduction velocity and normal MDL), moderate (decreased sensory conduction velocity and prolonged $\mathrm{MDL}$ ), and severe (no sensory response and prolonged MDL). Median nerve MDL (obtained with stimulation in the midline and $5-\mathrm{cm}$ away from the active recording electrode in the APB muscle) longer than $4 \mathrm{~ms}$, which is the upper limit of our laboratory's reference values, median nerve motor conduction velocity lower than $50 \mathrm{~m} / \mathrm{s}$, which is the lower limit of our laboratory's reference values, median and ulnar nerve sensory response amplitude lower than $15 \mathrm{mV}$, which is the upper limit of our laboratory's reference values, and median and ulnar nerve antidromic sensory conduction velocities lower than $40 \mathrm{~m} / \mathrm{s}$, which is the lower limit of our laboratory's reference values, were accepted to be pathological. In the sensory conduction study of the palmar cutaneous nerve, lower limits for negative peak latency and conduction velocity were accepted to be $2.69 \mathrm{~ms}$ and $35 \mathrm{~m} / \mathrm{s}$, respectively (5).

\section{Statistical Analysis}

For analyzing the data, SPSS 20.0 (Statistical Package for the Social Sciences Inc., Chicago, IL, USA) statistical software was used. Data were presented in percentage, mean \pm standard deviation, and median (25-75 th percentile) in the study. Categorical variables were assessed using the Chi-square test. The compliance of numerical variables with normal distribution was controlled with Kolmogorov-Smirnov test. For evaluating the differences between the groups, Kruskal-Wallis one-way ANOVA and Dunn's multiple comparison tests were employed. Moreover, $p<0.05$ was accepted to be adequate for the rejection of the null hypothesis.

\section{Results}

The study included 83 extremities electrophysiologically diagnosed with CTS and 33 extremities electrophysiologically normal (totally 116 extremities from 40 male and 18 female patients). The mean age of female patients was $51.95 \pm 10.73$ years and that of male patients was $54.28 \pm 6.71$ years. There was no statistically significant difference between them $(p>0.05)$.

In the evaluation of extremities with CTS (83 extremities) according to the severity of CTS, 43 extremities (37.1\%) were mild, 27 (23.3\%) were moderate, and 13 (11.2\%) were severe. In all 116 extremities, the sensory conduction study of the me- 
Table 1. The mean values of motor and sensory conduction studies of the median nerve and sensory conduction study of the median palmar cutaneous nerve according to the severity of carpal tunnel syndrome

\begin{tabular}{|c|c|c|c|c|}
\hline Carpal Tunnel Syndrome & None $(n=33)$ & Mild $(n=43)$ & Moderate $(n=27)$ & Severe $(n=13)$ \\
\hline Median palmar cutaneous nerve latency (ms) & $2.67 \pm 0.90$ & $2.69 \pm 0.59$ & $3.35 \pm 1.0$ & $3.73 \pm 0.18$ \\
\hline Median palmar cutaneous nerve amplitude $(\mu \mathrm{V})$ & $12.52 \pm 6.13$ & $12.50 \pm 6.34$ & $8.24 \pm 6.25$ & $7.54 \pm 1.94$ \\
\hline Median nerve motor distal latency (ms) & $3.19 \pm 0.31$ & $3.55 \pm 0.21$ & $4.40 \pm 0.42$ & $6.42 \pm 1.17$ \\
\hline Median nerve motor action amplitude $(\mu \mathrm{V})$ & $16.48 \pm 4.89$ & $16.25 \pm 3.03$ & $14.95 \pm 3.74$ & $11.43 \pm 2.80$ \\
\hline Median nerve sensory conduction velocity $(\mathrm{m} / \mathrm{s})$ & $44.95 \pm 3.30$ & $36.29 \pm 2.37$ & $27.96 \pm 4.59$ & \\
\hline
\end{tabular}

Table 2. The relationship between the severity of carpal tunnel syndrome and latency, amplitude and conduction velocities of the median palmar cutaneous nerve

\begin{tabular}{|c|c|c|c|c|c|}
\hline CTS & $\begin{array}{c}\text { None }(n=33) \\
\text { Median }(25-75 \%)\end{array}$ & $\begin{array}{c}\text { Mild }(n=43) \\
\text { Median }(25-75 \%)\end{array}$ & $\begin{array}{l}\text { Moderate }(n=27) \\
\text { Median }(25-75 \%)\end{array}$ & $\begin{array}{c}\text { Severe }(n=13) \\
\text { Median }(25-75 \%)\end{array}$ & $p$ \\
\hline PCBm latency (ms) & $2.5(2.1-2.8)$ & $2.6(2.5-2.8)$ & $2.9(2.6-3.0)$ & $3.1(2.7-3.5)$ & $b, c, d, e$ \\
\hline PCBm amp $(\mu \mathrm{V})$ & $12.0(7.10-15.0)$ & $11.0(7.47-15.00)$ & $8.30(8.30-8.70)$ & $6.5(4.75-7.60)$ & $b, c, d, e$ \\
\hline PCBm conduction velocity $(\mathrm{m} / \mathrm{s})$ & $37.00(32.8-41.85)$ & $35.70(28.60-38.65)$ & $25.80(21.60-29.60)$ & $23.40(23.70-29.30)$ & $b, c, d, e$ \\
\hline
\end{tabular}

PCBm: palmar cutaneous branch of the median nerve, CTS: Carpal Tunnel Syndrome

a: Statistically significant difference between normal extremities and extremities with mild CTS $(p<0.05)$

b: Statistically significant difference between normal extremities and extremities with moderate CTS $(p<0.05)$

c: Statistically significant difference between normal extremities and extremities with severe CTS $(p<0.05)$

$d$ : Statistically significant difference between extremities with mild CTS and extremities with moderate CTS ( $p<0.05$ )

e: Statistically significant difference between extremities with mild CTS and those with severe CTS $(p<0.05)$

f: Statistically significant difference between extremities with moderate CTS and those with severe CTS $(p<0.05)$

dian palmar cutaneous branch was performed. While pathology was found in 52 extremities (44.8\%) (prolonged sensory response latency, slower sensory conduction velocity, non-obtained sensory nerve action potential, etc.), no pathology was observed in 64 patients (55.2\%). The mean values of the motor and sensory conduction studies of the median nerve and sensory conduction study of the median palmar cutaneous nerve are presented in Table 1.

While no pathology related to the sensory conduction study of the median palmar cutaneous nerve was found in the extremities without CTS, pathology was seen in 52 of the extremities with CTS (62.7\%). This result was statistically significant $(p<0.05)$.

In all extremities with mild CTS, the sensory action potential of the median palmar cutaneous nerve was obtained. However, the sensory action potential of the median palmar cutaneous nerve could not be obtained in $18.5 \%(5 / 27)$ of the extremities with moderate CTS and in $46.1 \%(6 / 13)$ of the extremities with severe CTS.

In the evaluation with regard to the severity of CTS, while PCBm pathology was detected in $37.2 \%$ of extremities with mild CTS (16/43), PCBm pathology was observed in $92.6 \%$ of the extremities with moderate CTS $(25 / 27)$ and $84.6 \%$ of the extremities with severe CTS (11/13). Accordingly, when the ex- tremities with mild and moderate CTS and those with mild and severe CTS were evaluated with regard to a pathology of the sensory conduction study of the palmar cutaneous nerve, the relationship between them was found to be statistically significant $(p<0.05)$. However, the difference between the extremities with moderate and severe CTS was statistically insignificant ( $p>0.05)$.

In the evaluation of the amplitudes and latencies of sensory nerve action potentials and $\mathrm{PCBm}$ sensory conduction velocities according to the severity of CTS, while minimal correlation was found between CTS severity and PCBm conduction velocity (correlation coefficient of 0.188 and significance of 0.54 ), a high correlation with PCBm latency and amplitude was observed (correlation coefficient of 0.306 and 0.318 , respectively, and significance of 0.002 and 0.001 , respectively). Moreover, while the relationship between the extremities with normal and mild CTS and those with moderate and severe CTS was significant $(p<0.05)$, the difference between the extremities with normal and mild CTS and those with moderate and severe CTS was statistically insignificant ( $p>0.05$ ) (Table 2).

\section{Discussion}

The median palmar cutaneous nerve is a small branch of the median nerve that provides sensory innervations of the thenar region (4). Anatomically, $\mathrm{PCBm}$ originates from approximately 
$5.5 \mathrm{~cm}$ proximal to the radial styloid in the radial side of the median nerve (5). PCBm passes through its own 9-16 mm long tunnel in the medial of the flexor carpi radialis tendon by intercrossing the transverse carpal ligament (5). Because it does not pass through the carpal tunnel, it is not affected by CTS.

CTS is the entrapment of the median nerve at the level of the carpal tunnel, and it is a classic example of chronic compression neuropathies. Nerve conduction studies, which were conducted for diagnosis in addition to clinical findings, constitute the golden standard $(10,11)$. The appropriate demonstration of abnormal isolated transcarpal median nerve conduction is the most ideal nerve conduction study (8). Therefore, comparative studies on nerves with the least possibility of susceptibility in the presence of CTS are of vital importance (12). PCBm, which provides the innervations of the thenar region and does not pass through the carpal tunnel, has been recommended as the comparative nerve in CTS for this aim (5). However, the synchronous detection of PCBm abnormalities with CTS has decreased the reliability of this nerve in comparative tests. Chang and Lien (5) were the first to report that some data conflicted with each other in the PCBm nerve conduction study in CTS and normal patients. Rathakrishnan et al. (7) also reported PCBm abnormalities in $46 \%$ of CTS patients. Although, the significant age difference between the groups in their study explained the slowing in PCBm sensory conduction velocities in the presence of CTS, similar results were also obtained in age-matched analysis. Wada et al. (9) reported a PCBm entrapment in a case with CTS after a surgical examination. On the other hand, in the study by Imai et al. (8), an abnormality in PCBm conduction study was observed in 3 of 8 CTS patients. In our study, there was no difference between age groups, and abnormalities in the PCBm conduction study were found in $62.7 \%$ of the patients with CTS.

In studies on PCBm in literature, the evaluation of CTS patients according to severity was not performed. On the other hand, in our study, the relationship between the severity of CTS and PCBm conduction studies was investigated. When the CTS patients were classified according to their severity, an electrophysiological abnormality was detected in $84.6 \%$ of patients with severe CTS, but no PCBm sensory action potential was obtained in $46.1 \%(6 / 13)$. While an electrophysiological abnormality was detected in $92.6 \%$ of the patients with moderate CTS, PCBm sensory action potential was not found in $18.5 \%$ $(5 / 27)$. In all patients with mild CTS, PCBm sensory action potential was obtained, and an electrophysiological abnormality was observed in $37.2 \%$. The PCBm sensory conduction study within normal intervals in all patients without CTS showed that PCBm can be affected in CTS patients according to the severity.

In the surgical examination of patients with a PCBm abnormality in the study by Imai et al. (8), an entrapment from the radial side of the palmaris longus tendon and facial band and an entrapment coursing too close and parallel to the main branch of the median nerve in 1 patient were reported. While no spaceoccupying lesion was observed in any patient in this study, a ganglion compressing on $\mathrm{PCBm}$ was reported in two previous studies $(13,14)$.
It is not exactly known whether the entrapments of PCBm and the main branch of the median nerve are independent of each other, whether they are together, or why they coexist. However, there are some theories that have been suggested. According to anatomical studies, $\mathrm{PCBm}$ passes the wrist through its own channel that is $9-16 \mathrm{~cm}$ in length, which makes the nerve susceptible to be entrapped in that region (8). The second reason is the thought that the entrapment is related to increased stretching at the exit point from the wrist due to decreased mobility and decreased shift features of the main branch of the median nerve in CTS (7). The third reason is that it may result from proximal degeneration caused by retrograde degeneration, which can be thought to be due to the high frequency of susceptibility, especially in patients with moderate and severe CTS. However, further studies are needed for the confirmation of this theory.

In our study, the finding of an intense abnormality in PCBm might have resulted from using the reference values of Chang and Lien (5) instead of our reference values and from obtaining results of conduction velocities at wider intervals due to studying the technique in a short segment.

\section{Conclusion}

PCBm susceptibility can be seen in all CTS cases, but it is more intense in patients with moderate and severe CTS. The susceptibility of PCBm even in mild cases makes the use of this test as a comparative test in CTS more difficult.

Ethics Committee Approval: Ethics committee approval was received for this study from the ethics committee of Ankara Physical Medicine and Rehabilitation Education and Research Hospital.

Informed Consent: Written informed consent was obtained from patients who participated in this study.

Author Contributions: Concept - B.S.; Design - B.S.; Supervision - A.K., M.A.; Resource - B.S., B.Ö., I.S.; Materials - B.S., B.Ö.; Data Collection and/or Processing - B.S., B.Ö.; Analysis and/or Interpretation - B.S., M.A.; Literature Review - M.I., A.K., E.Y., I.S.; Writer - B.S.; Critical Review - M.I., A.K., I.S., E.Y.

Peer-review: Externally peer-reviewed.

Conflict of Interest: No conflict of interest was declared by the authors.

Financial Disclosure: The authors declared that this study has received no financial support.

\section{References}

1. Practice parameter for carpal tunnel syndrome (summary statement). Report of the Quality Standards Subcommittee of the American Academy of Neurology. Neurology 1993;43:2406-9. [CrossRef]

2. Jackson DA, Clifford JC. Electrodiagnosis of mild carpal tunnel syndrome. Arch Phys Med Rehabil 1989;70:199-204.

4. Hobbs RA, Magnussen PA, Tonkin MA. Palmar cutaneous branch of the median nevre. J Hand Surg Am 1990;15:38-43. [CrossRef] 
5. Chang CW, Lien IN. Comparison of sensory nevre conduction in the palmar cutaneous branch and first digital branch of the median nevre: a new diagnostic method for carpal tunnel syndrome. Muscle Nerve 1991;14:1173-6. [CrossRef]

6. Ayse TB, Feride G, Sümer G, Isik K, Mustafa G. The role of sensory nevre conduction study of the palmar cutaneous nevre in the diagnosis of carpal tunnel syndrome in patients with polyneuropathy. Neurol India 2007;55:17-21. [CrossRef]

7. Rathakrishnan R, Therimadasamy AK, Chan YH, Wilder-Smith EP. The median palmar cutaneous nevre in normal subjects and CTS. Clinical Neurophysiol 2007;118:776-80. [CrossRef]

8. Imai T, Wada T, Matsumoto H. Entrapment neuropathy of the palmar cutaneous branch of the median nevre in carpal tunnel syndrome. Clinical Neurophysiol 2004;115:2514-7. [CrossRef]

9. Wada T, Imai T, Ishii S. Entrapment neuropathy of the palmar cutaneous branch of the median nevre concomitant with carpa tunnel syndrome: a case report. J Hand Surg Br 2002;27:583-5. [CrossRef]
10. Werner RA, Andary M. Carpal tunnel syndrome: pathopysiology and clinical neurophysiology (Review). Clin Neurophysiol 2002;113:1373-81. [CrossRef]

11. Jablecki CK, Andary MT, Floeter MK, Miller RG, Quartly CA, Vennix MJ, et al. Practice parameter: electrodiagnostic studies in carpal tunnel syndrome. Report of the American Association of Electrodiagnostic Medicine, American Academy of Neurology and American Academy of Physical Medicine and Rehabilitation. Neurology 2002;58:1589-92. [CrossRef]

12. Bodofsky EB, Wu KD, Campellona JV, Greeberg WM, Tomaio AC. A sensitive new median-ulnar tecnique for diagnosing mild carpal tunnel syndrome. Electromyogr Clin Neurophysiol 2005;45:139-44.

13. Buckmiller FJ, Rickard TA. Isolated compression neuropathy of the palmar cutaneous branch of the median nerve. J Hand Surg Am 1987;12:97-9. [CrossRef]

14. Haskin JS Jr. Ganglion-related compression neuropathy of the palmar cutaneous branch of the median nerve: a report of two cases. J Hand Surg Am 1994;19:827-8. [CrossRef] 